\title{
Design and Fabrication of Digitalised Total Indicated Run-out Testing machine for conveyor idlers
}

\author{
V. Savithiri, S. Arjun* and S. V. Abil Das \\ Department of Mechanical Engineering, St. Joseph's Institute of Technology, Old Mamallapuram Road, Semmancheri, Chennai, Tamil Nadu \\ 600119 , India
}

Received 01 Feb 2018, Accepted 05 April 2018, Available online 09 April 2018, Vol.8, No.2 (March/April 2018)

\begin{abstract}
There were few difficulties faced in the total indicated run out testing of industrial conveyor idlers, such as separate apparatuses for testing various sizes of idlers, human observation error occurrence due to the usage of analog dial gauges, time consuming due to manual operation for the rotation of idlers, difficulties in formulating the output manually. Considering all the difficulties faced in total indicated run out testing of idlers. Design and fabrication of the newly proposed machine is done. They can accommodate idlers up to three meters in single apparatus by using adjustable V-block in guide ways in order to counter the change of idlers for various sizes. To counter the problem of human observation error, digitalized dial gauges are used for easy observation of values. The idlers are rotated by means of high torque DC geared motor to take reading at 12,3,6,9'O clock respectively. The output values are being fed to the computer system by means of usb to overcome manual observation of values. We can observe that difficulties faced in manual run out testing are overcome and the testing process becomes easier.
\end{abstract}

Keywords: Automated TIR testing machine for circular objects made in industrial standards

\section{Introduction}

Total indicator run-out is the difference between the maximum and minimum measurements, that is, readings of an indicator, on the planar, cylindrical, or contoured surface of a part, showing its amount of deviation from flatness, roundness (circularity), cylindricity, concentricity with other cylindrical features, or similar conditions.

Sources of TIR

- Lobing of the shaft

- Tool chatter

- Improper feed rate and speed of cutting tools

- Dents from handling

- Rust patches

- Defective or worn bearings in the machine or lathe supports

In this project we are going to measure TIR values of Conveyor idlers which are used in industries to convey heavy cargo using newly fabricated machine which makes the process faster and easier

*Corresponding author's ORCID ID: 0000-0002-3313-406X, DOI: https://doi.org/10.14741/ijcet/v.8.2.21

\section{Demerits of TIR}

- Increases the belt noise due to point contact on idlers.

- Decreases the belt speeds due to ovalty of idlers.

- Decreases the bearing life of idlers.

- Increases the maintenance cost of conveyor equipment

\section{Components of TIR testing machine}

- Frame

- V-Block

- Digital dial indicator

- Toggle clamp

- High torque DC Geared motor

- Analog servo motor

- Tracked wheel

- Arduino control board

\section{Working principle of TIR testing machine}

The idler of specific length and diameter is to be chosen. The shafts of the idler are simply supported by means of V-block and toggle clamp are locked at both ends to avoid jumping of idlers during rotational motion. The arduino control board is switched on. Tracked wheel sets the idler to 12 'O clock position; 
analog servo motor initially lifts the indicator needle. At 12 ' 0 clock position it drops the needle and one set of TIR values are recorded into the computer system. Then, servo motor lifts the needle and tracked wheel moves the idler to 3'0 clock position. The needle drops and next set readings are recorded in the system. This step keeps on repeating for next two clock positions and the program runs an algorithm and tells whether idler values are matched with Theoretical TIR values; tells whether the idler is OK or NOT OK.

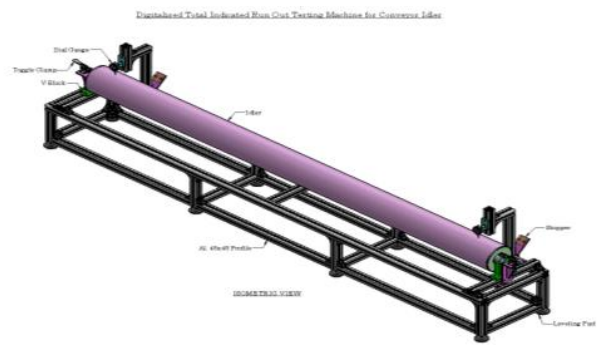

Fig.1 digitalised tir testing machine

\section{Calculation}

\section{Motor load calculation}

Assume,

Idler length, $\mathrm{l}=2000 \mathrm{~mm}$

Idler diameter, $\mathrm{d}=139.4 \mathrm{~mm}$

Angular force, $\mathrm{w}=5 \mathrm{~kg}$

Torque, $\mathrm{T}=$ force $*$ perpendicular distance

$=5^{*}(69.7 / 1000)=0.3485 \mathrm{Kg} \cdot \mathrm{m}$.

Assume $1 \mathrm{rpm}=1 \mathrm{rev} / \mathrm{min}$

Horse Power $(\mathrm{HP})=2 \pi \mathrm{NT} / 4500$

$=2 * 3.14 * 1 * 0.3485 / 4500$
$=4.86 \times 10^{\wedge}-4$

HP to Watt $=4.86 \times 10^{\wedge}-4^{*} 0.746$

$* 1000$

$=0.362 \mathrm{Watt}$

$\cong 0.5 \mathrm{Watt}$.

\section{Maximum deflection of idlers}

We know that maximum deflection of simply supported beam subjected to udl,

$y_{\max }=5 \mathrm{w} l^{4} / 384 \mathrm{EI}$

Moment of inertia, $\mathrm{I}=\pi d_{o}^{4} / 64$

Idler length, $\mathrm{l}=2000 \mathrm{~mm}$

Idler outer dia, $d_{o}=152.4 \mathrm{~mm}$

$\mathrm{I}=\pi \times 152.4^{4} / 64$

$=4.23 \times 10^{8} \mathrm{~mm}^{4}$

$\mathrm{E}=2 \times 10^{5} \mathrm{~N} / \mathrm{mm}^{2}$

$\mathrm{W}=50 \mathrm{~kg}$

$y_{\text {max }}=5 \times 50 \times 2000^{4} / 384 \times 2 \times 10^{5} \times 4.23 \times 10^{8}$

$=1.20 \mathrm{~mm}$.

\section{Abbreviations}

E - Young's modulus $\left(\mathrm{N} / \mathrm{mm}^{2}\right)$

$\mathrm{D}$ - Diameter of the idler (mm)

$\mathrm{T}$ - Thickness of the material (mm)

$\mathrm{N}$ - Speed of the motor (rpm)

HP - Horse power (dimensionless)

$\mathrm{T}$ - Torque (kg.m)

I - Moment of inertia $\left(\mathrm{mm}^{4}\right)$

$\mathrm{v}-\operatorname{Velocity}(\mathrm{m} / \mathrm{s})$

W- Angular force $(\mathrm{kg})$

$y_{\text {max }}$ - Maximum deflection (mm)

Table.1 Data collection from existing and proposed TIR testing machine

\begin{tabular}{|c|c|c|c|c|c|c|c|c|c|}
\hline \multirow{5}{*}{$\begin{array}{c}\text { Idler } \\
\text { length \& } \\
\text { diameter }\end{array}$} & \multirow{2}{*}{\multicolumn{6}{|c|}{ Idler manufacturer }} & Theoretical & Time & Time \\
\hline & & & & & & & TIR & taken & taken \\
\hline & \multicolumn{2}{|c|}{ Elecon } & \multicolumn{2}{|c|}{ Arudra } & \multicolumn{2}{|c|}{ Aswamegh } & values & in & in \\
\hline & \multicolumn{6}{|c|}{ Practical TIR values in $\mathrm{mm}$} & in & sec & sec \\
\hline & $\begin{array}{c}\text { Old } \\
\text { machine }\end{array}$ & $\begin{array}{c}\text { New } \\
\text { machine }\end{array}$ & $\begin{array}{c}\text { Old } \\
\text { machine }\end{array}$ & $\begin{array}{c}\text { New } \\
\text { machine }\end{array}$ & $\begin{array}{c}\text { Old } \\
\text { machine }\end{array}$ & $\begin{array}{c}\text { New } \\
\text { machine }\end{array}$ & $\mathbf{m m}$ & (Old) & (New) \\
\hline Length & \multirow{4}{*}{1.29} & \multirow{4}{*}{1.05} & \multirow{4}{*}{1.45} & \multirow{4}{*}{1.18} & \multirow{4}{*}{1.32} & \multirow{4}{*}{1.18} & \multirow{4}{*}{$0.8-1.0$} & \multirow{4}{*}{120} & \multirow{4}{*}{30} \\
\hline $530 \mathrm{~mm}$ & & & & & & & & & \\
\hline Diameter & & & & & & & & & \\
\hline $152.4 \mathrm{~mm}$ & & & & & & & & & \\
\hline Length & \multirow{4}{*}{1.58} & \multirow{4}{*}{1.15} & \multirow{4}{*}{1.64} & \multirow{4}{*}{1.39} & \multirow{4}{*}{1.52} & \multirow{4}{*}{1.27} & \multirow{4}{*}{$1.0-1.4$} & \multirow{4}{*}{180} & \multirow{4}{*}{45} \\
\hline $670 \mathrm{~mm}$ & & & & & & & & & \\
\hline Diameter & & & & & & & & & \\
\hline $152.4 \mathrm{~mm}$ & & & & & & & & & \\
\hline Length & \multirow{4}{*}{1.85} & \multirow{4}{*}{1.25} & \multirow{4}{*}{1.75} & \multirow{4}{*}{1.38} & \multirow{4}{*}{1.69} & \multirow{4}{*}{1.45} & \multirow{4}{*}{$1.2-1.6$} & \multirow{4}{*}{240} & \multirow{4}{*}{60} \\
\hline $1000 \mathrm{~mm}$ & & & & & & & & & \\
\hline Diameter & & & & & & & & & \\
\hline $139.7 \mathrm{~mm}$ & & & & & & & & & \\
\hline Length & \multirow{4}{*}{1.95} & & & & & & & & \\
\hline $2000 \mathrm{~mm}$ & & 142 & 205 & 159 & 214 & 167 & 14-18 & 300 & 90 \\
\hline Diameter & & 1.42 & 2.05 & 1.59 & 2.14 & $1.6 /$ & $1.4-1.8$ & 300 & 90 \\
\hline $139.7 \mathrm{~mm}$ & & & & & & & & & \\
\hline
\end{tabular}




\section{Data comparison}

Idler of various manufacturers and lengths are being tested for TIR values using old apparatus and new apparatus which are tabulated in table 1 . Time taken to measure the TIR values using old and new machine are tested and tabulated in table 1

\section{Result and Discussion}

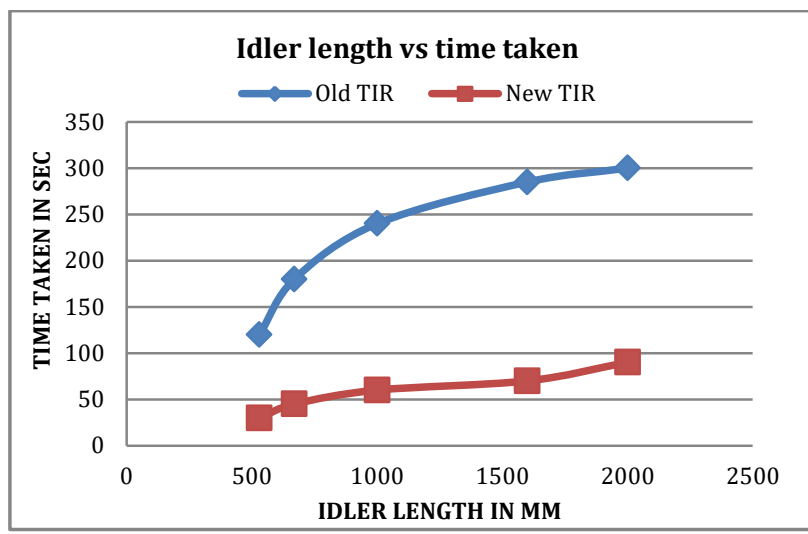

For our practical examination purpose we have taken idlers manufactured by three companies' namely elecon, arudra, aswamegh respectively to check out their range of accuracy of TIR values between them. The line chart below explains the difference in their accuracies.

From the line chart we can inferred that theoretical TIR values are intact with practical TIR values for the idlers manufactured by elecon. It is recommended for the industries to use elecon idlers in their rollers to increase belt life and other factors.

\section{Conclusion}

From the results we can see that the accuracy of readings taken from digitalised TIR testing machine is increased. So the difficulty caused due to error are minimised and avoided.

The difficulty experienced by the observer to take readings and tabulate it has been rectified and time taken for taking the readings is considerably reduced.
Time management has been a great factor during production and testing of components in industries. Time is one of the main factors that determine the component profit rate. It has been inferred from the table that time has been reduced effectively which leads to testing of more number of idlers and also helps in some financial aspects. This can inferred from the comparison done in line chart below.

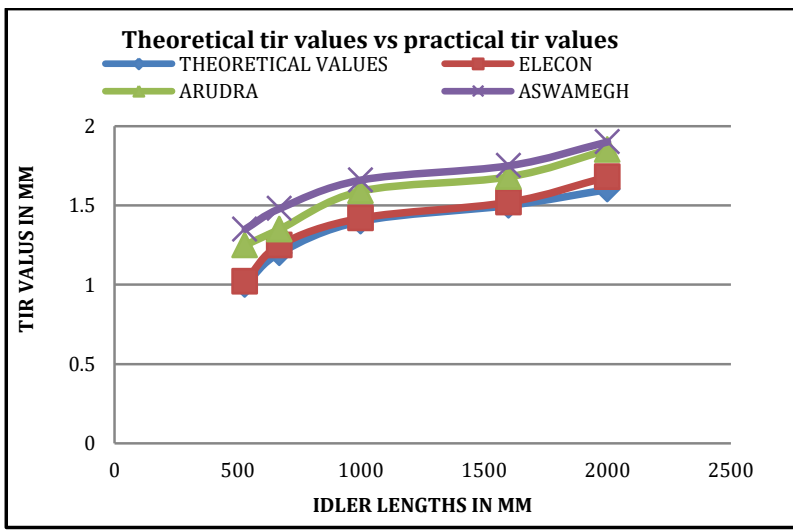

Usually in old TIR testing machine an observer usually takes around 3-6 minutes depending on the size of idler, the time gets reduced by below 1 minute whatever may be the size of idler. On an average he takes only 100 minutes to test 100 idlers. That is a healthy amount of time which can give a handful of positive results.

Due to this modification stagnation of idlers before testing stage reduces in number and provides less tension to the company and causes a huge benefit in financial aspects. In the same apparatus various sizes of idlers are tested which reduces unnecessary transportation of idlers to various parts of the company.

\section{References}

CEMA, Conveyor Equipment ManufacturersAssociation Handbook, USA, 1997

Conveyor idlers - SANS 1313 and selection procedures, Adriano Frittella and Simon Curry, IMHC

Bureau of Indian Standards, Idler and Idler sets for belt conveyor - Specification(Second Revision of IS 8598) ICS 53.040 .01

Elecon conveyor idlers catalogue. 